\title{
Late cardiac effects after treatment for childhood Hodgkin's disease with chemotherapy and low-dose radiotherapy
}

\author{
I Ilhan, F Sarialiog̈lu, N Özbarlas, M Büyükpamukçu, C Akyüz, T Kutluk
}

Dr Sami Ulus Childrens' Hospital, Ankara, Turkey I Ilhan

Department of
Pediatric Oncology,
Dokuz Eylül
University Institute of
Oncology, 35340
Izmir, Turkey
F Sarialioglu

Department of Pediatric Cardiology, Cukurova University Faculty of Medicine, Adana, Turkey NÖzbarlas

Department of Pediatric Oncology, Hacettepe University Institute of Oncology, O6 100 Ankara, Turkey M Büyükpamukçu

C Akyüz

T Kutluk

Correspondence to I Ilhan, 37 Solak $43 / 906500$,

Bahcelievler, Ankara, Turkey

Accepted 23 November 1994

\begin{abstract}
Summary
Twenty-four patients under 18 years when treated for Hodgkin's disease (20 male, four female) were examined no less than five years after the completion of the treatment. The mean age was 17 years (range 9.5-25.0 years) at the time of study. All patients received six courses of cyclophosphamide - oncovin - procarbazine prednisolone chemotherapy; in addition, nine patients received low-dose radiotherapy excluding the mediastinum and eight of 24 patients received mediastinal radiotherapy; the dose was between 20-30 Gy. All patients had normal cardiovascular findings on clinical examination. ECG and chest radiography were within normal limits in all patients. Resting left ventricular ejection fraction and fractional shortening were decreased in only one patient $(4 \%)$, but there was no significant difference between the patient group and a control group for left ventricular systolic function $(p>0.05)$. In the patient group, early diastolic peak velocity, peak velocity at atrial contraction, left ventricular isovolumic relaxation time, and the rate of decrease of flow velocity in early diastole were signifcantly different from that of the control group $(p<0.05)$. In conclusion, the late effects of our treatment protocol for Hodgkin's disease appear to be minimal. These observations support combined modality, low-dose irradiation regimens in children and adolescents and suggest the need for careful cardiac screening of treated patients.
\end{abstract}

Keywords: late effects, cardiac functions, Hodgkin's disease, childhood

\section{Introduction}

The cure rate for Hodgkin's disease has now reached $85-90 \%$ in early and approximately $70-80 \%$ in late stages. However, as the cure rate has increased, the late complications of treatment have assumed more importance, especially in young patients. ${ }^{1-3}$ Early and late cardiac effects are among these complications and the literature contains a wide range of reports of cardiac complications such as different forms of pericarditis, valvular abnor- malities, restrictive cardiomyopathy, and coronary artery stenoses. ${ }^{4-8}$

We have evaluated cardiac functions in 24 patients who had previously received radiotherapy and/or combined chemotherapy for Hodgkin's disease and who were now considered to have a normal life expectancy.

\section{Patients and methods}

All patients with a diagnosis of Hodgkin's disease, who had been treated at the Department of Pediatric Oncology, Hacettepe University Institute of Oncology between January 1972 and December 1985 were reviewed. The study included patients who had completed treatment at least five years prior to the end of December 1990 and were in continuous complete remission. We selected 24 disease-free survivors fulfilling these criteria.

All the patients were examined by the same cardiologist (NÖ). Their effort capacity was examined by asking questions about their daily activities graded according to the New York Heart Association standards. ${ }^{9}$ In addition, a standard 12-lead electrocardiogram (ECG), and a telecardiographic film in two directions at right angles for calculation of heart volumes, were obtained at the time of the study. 2D, M-mode and Doppler echocardiographic equipment (Toshiba, Japan) with transducers of 5, 3.75, and $2.5 \mathrm{MHz}$ were used. The study was performed using standard techniques and recorded on dry silver paper at a speed of $50 \mathrm{~mm} / \mathrm{s}$ simultaneously with a 12-lead ECG. Left ventricular end-systolic dimension (LVESD), left ventricular end-diastolic dimension (LVEDD), ejection fraction (EF) and fractional shortening (FS) were measured to evaluate systolic heart functions Left ventricular ejection and fractional shortening were reported as a percentage of normal; $50 \%$ and $30 \%$ were accepted as normal limits, respectively.

Doppler echocardiographic examination of mitral inflow was performed from the apical four-chamber view with the sample volume placed at the mitral valve annulus. Measurements included: early diastolic peak velocity (E), peak velocity at atrial contraction $(A)$, the ratio of early to late time velocity $(E / A)$, isovolumic relaxation time (time from onset of the second heart sound to onset of mitral flow), deceleration time (time from peak early dia- 
stolic velocity to baseline) and the rate of decrease of flow velocity in early diastole (EF slope).

We divided the 24 patients into two groups according the treatments received.

Group 1 Included 16 patients, 15 males and one female who had received six courses of cyclophosphamide - oncovin - procarbazine prednisolone (COPP) chemotherapy; in addition nine of 16 patients had received radiotherapy excluding the mediastinum.

Group 2 Included eight patients, five males and three females who had received six courses of COPP chemotherpy and mediastinal radiotherapy. The dose was between 20-30 Gy.

No patient in either group had a history of smoking. The COPP chemotherapy protocol consist of cyclophosphamide $\left(600 \mathrm{mg} / \mathrm{m}^{2}\right.$ intravenously, 1 and 8 days $)$, vincristine $\left(1.4 \mathrm{mg} / \mathrm{m}^{2}\right.$ intravenously, 1 and 8 days, procarbazine (100 $\mathrm{mg} / \mathrm{m}^{2}$ orally, $1-14$ days) and prednisone ( $40 \mathrm{mg} / \mathrm{m}^{2}$ orally, $1-14$ days).

The cardiac functions of patients were com-

Table 1 Mean (standard deviation) of the cardiac function tests and some clinical findings in the different treatment groups

\begin{tabular}{|c|c|c|c|}
\hline & $\begin{array}{l}\text { Group I } \\
(\text { mantle } R T(-) \\
C O P P \times 6)\end{array}$ & $\begin{array}{l}\text { Group } I I \\
(\text { mantle } R T(+) \\
C O P P \times 6)\end{array}$ & $p$ \\
\hline Patients $(n)$ & 16 & 8 & \\
\hline \multicolumn{4}{|l|}{ Age (year) } \\
\hline At diagnosis & $7.78(3.81)$ & $11.43(4.37)$ & \\
\hline At study & $17.21(5.12)$ & $17.81(5.04)$ & \\
\hline \multicolumn{4}{|c|}{ Systolic functions: } \\
\hline LVESD & $30.43(5.84)$ & $27.50(3.11)$ & $>0.05$ \\
\hline LVEDD & $48.31(5.77)$ & $44.87(2.90)$ & $>0.05$ \\
\hline EF & $67.12(9.36)$ & $68.25(9.14)$ & $>0.05$ \\
\hline FS & $37.50(7.58)$ & $38.62(7.32)$ & $>0.05$ \\
\hline \multicolumn{4}{|c|}{ Diastolic functions: } \\
\hline $\mathbf{E}$ & $0.94(0.26)$ & $0.87(0.22)$ & $>0.05$ \\
\hline A & $0.57(0.16)$ & $0.61(0.13)$ & $>0.05$ \\
\hline $\mathbf{E} / \mathbf{A}$ & $1.65(0.22)$ & $1.57(0.32)$ & $>0.05$ \\
\hline IRT & $48.81(9.32)$ & $48.12(7.24)$ & $>0.05$ \\
\hline EF slope & $5.05(1.57)$ & $5.05(3.15)$ & $>0.05$ \\
\hline
\end{tabular}

LVESD: left ventricular end-systolic dimension; LVEDD: left ventricular enddiastolic dimension; EF: ejection fraction; FS: fractional shortening; E: earlydiastolic peak velocity; A: peak velocity at atrial contraction; E/A: ratio of early to late time velocity; IRT: isovolumic relaxation time (time from onset of the second heart sound to onset of mitral flow); EF slope: rate of decrease of flow velocity in early diastole.

Table 2 Mean (standard deviation) of the cardiac function tests in the patient group (Group $1+$ Group 2) and control group

\begin{tabular}{lllll} 
& $\begin{array}{l}\text { Patient } \\
\text { group }\end{array}$ & $\begin{array}{l}\text { Control } \\
\text { group }\end{array}$ & $p$ \\
\hline $\begin{array}{l}\text { Systolic functions: } \\
\text { LVESD }\end{array}$ & $29.45(5.21)$ & $30.00(5.95)$ & $>0.05$ \\
LVEDD & $47.00(5.39)$ & $47.06(5.57)$ & $>0.05$ \\
EF & $67.16(9.15)$ & $65.60(10.88)$ & $>0.05$ \\
FS & $37.58(7.40)$ & $36.63(8.32)$ & $>0.05$ \\
Diastolic functions: & & & & \\
E & $0.92(0.24)$ & 0.97 & $(0.26)$ & $<0.05$ \\
A & $0.58(0.15)$ & 0.61 & $(0.16)$ & $<0.05$ \\
E/A & $1.62(0.25)$ & 1.66 & $(0.27)$ & $>0.05$ \\
IRT & $48.58(9.45)$ & 57.67 & $(9.07)$ & $<0.05$ \\
EF slope & $5.07(2.14)$ & 7.22 & $(2.25)$ & $<0.05$ \\
\hline
\end{tabular}

See table 1 for abbreviations. pared to a control group of 30 age- and sexmatched healthy Turkish children.

Variation analysis, Student's $t$-test and regression analysis were used for statistical analysis where appropriate. Results were considered significant at a value of $p<0.05$.

\section{Results}

The study group consisted of 20 males and four females. The mean age was $17.41 \pm 4.98$ years (range 9.5-25 years) at the time of study. The mean age at the time of diagnosis was $9.00 \pm$ 4.29 years (range 3-17 years). The period of follow-up from completion of treatment to study was $8.15 \pm 3.25$ years (range $5-16$ years).

All patients were staged according to the Ann Arbor classification: seven stage IA, two stage IB, six stage IIA, one stage IIB, two stage IIIA, three stage IIIB, one stage IVA, and two stage IVB.

No patients had evidence of cardiovascular abnormalities on clinical examination; in particular there was no evidence of cardiomegaly, left ventricular failure, pericardial effusion, or constrictive pericarditis. In all patients, the ECG and cardiac silhouette on chest radiography were within normal limits. All patients were in New York Heart Association function class 1 according to their exercise capacity.

We did not find any significant difference between Group 1 and Group 2 in cardiac functions (table 1). Therefore we combined these two groups and compared them with the control group (table 2).

In one patient, the EF and FS were diminished, being $44 \%$ and $21 \%$, respectively, at rest compared with $65.6 \%$ and $36.6 \%$, respectively, for the group as a whole. The LVESD was increased, $(42.3 \pm 3.5)$ in this patient, compared with a mean value of $27.3 \pm$ 3.4 in the control group. There was no significant difference between the patient and control groups with respect to the left ventricular systolic function $(\mathrm{p}>0.05)$.

In the patient group, left ventricular isovolumic relaxation time was prolonged compared with the control group ( $\mathrm{p}<0.05)$.

Although relaxation time was delayed, a relative increase in the blood flow across the mitral valve in diastole (early diastolic peak velocity $=\mathrm{E}$ ) was demonstrated. A significant difference between the patient and control groups was found in early diastolic flow velocity $(\mathrm{p}<0.05)$. This may be due to $a$ ) large LVESD, or $b$ ) incomplete emptying of the atria in diastole. To determine the main reason the correlation of $\mathrm{E}$ and LVESD was calculated, but no correlation was found $(r=0.11)$. If the reason for the increase in early diastolic peak velocity were incomplete emptying of the atria in diastole, then the atria would try to send the remaining diastolic blood to the ventricles in systole, thus causing an increase in peak velocity at atrial contraction (A). To investigate this, the correlation between $\mathrm{A}$ and $\mathrm{E}$ was determined and a positive correlation was found $(r=0.81)$. Also the peak velocity at atrial contraction was significantly different between the two groups $(\mathrm{p}<0.05)$. 


\section{Discussion}

The literature contains a number of reports on cardiac complications, often severe, following mantle field irradiation but many of these reports concern treatment techniques now considered out-of-date. ${ }^{10-13}$

Pohjola et $a l^{11}$ reported an incidence of $38 \%$ of pericardial effusion more than five years after mediastinal irradiation. There were no abnormalities on physical examination and no pericardial effusion in our patients.

Although the incidence of ECG abnormalities in patients who received mantle irradiation was $25 \%$ including ST segment depression. T-wave changes, minor QRS abnormalities and occasional silent myocardial infarction reported, we did not find ECG abnormalities in our patients. Morgan et al $^{1}$ found normal ECG results in 25 Hodgkin's disease patients who were evaluated 5 to 16 years after $40 \mathrm{~Gy}$ to a mantle field with subcarinal block placement at $30 \mathrm{~Gy}$. Gottdiener et al $^{12}$ reported ECG abnormalities in 12 of 25 patients treated with anterior fields an average of 10.9 years following radiation. In another study, $46 \%$ of 28 patients screened more than five years after irradiation between 12 and 38 years of age had ECG abnormalities. ${ }^{11}$

In our study, abnormal left ventricular systolic function was found in only one patient in whom the ejection fraction and fractional shortening were decreased. On the other hand, the left ventricular end-systolic dimensions were significantly higher in this patient than in the group as a whole. All of these findings indicated cardiomyopathy, however this was subclinical as his performance of daily activities, physical examination, ECG, and chest radiography were within normal limits. There was no significant difference between the patient and control groups when they were compared for systolic functions $(\mathrm{p}>0.05)$. This incidence of cardiac abnormality is less than previously reported. Burns et $\mathrm{ll}^{14}$ found a $57 \%$ incidence of abnormal ventricular function, but their patients had received doses of irradiation of up to $76 \mathrm{~Gy}$, which is in excess of the usual therapeutic range. A similar incidence of abnormalities of ventricular function was reported by Gottdiener et $a l^{12}$ but this group had been treated with a single antero-posterior field, a technique not commonly used. The low incidence of cardiotoxicity in our pediatric population following chest radiotherapy and COPP chemotherapy parallels the results

1 Morgan GW, Freeman AP, McLean RG, Jarvie BH, Giles RW. Late cardiac, thyroid and pulmonary sequelae of mantle radiotherapy for Hodgkin's disease. Int $\mathcal{f}$ Radia Oncol Biol 1985; 11: 1925-31.

2 Watchie J, Coleman CN, Raffin TA, et al. Minimal longterm cardiopulmonary dysfunction following treatment for Hodgkin's disease. Int f Radiat Oncol Biol 1987; 13: 517-24.

3 Mefferd JM, Donaldson SS, Link MP. Pediatric Hodgkin's disease; pulmonary, cardiac and thyroid function following combined modality therapy. Int $\mathcal{F}$ Radiat Oncol Biol 1989; 16: $679-85$.

4 Allavena C, Conroy T, Aletti P, Bey P, Lederlin P. Late cardiopulmonary toxicity after treatment for Hodgkin's cardiopulmonary toxicity after treatm

5 Makinen L, Makipernaa A, Rautonen J, et al. Long-term cardiac sequela after treatment of malignant tumors with radiotherapy or cytostatics in childhood. Cancer 1990; 65 radiotherap
$1913-7$. reported by Allavena $e t ~ a l^{4}$ in an adult population. We evaluated cardiac functions by echocardiography; if we had used thallium scintigraphy, which is highly sensitive and specific in detecting abnormal myocardial perfusion, the incidence of abnormalities would probably have been higher. However, we attribute this lower incidence to the use of equally weighted fields given daily, a limited dose of $30 \mathrm{~Gy}$ in the mediastinum, and subcarinal blocks.

There are few reports of studies on left ventricular diastolic functions after the treatment of Hodgkin's disease in the literature. ${ }^{15}$ We evaluated our patients' left ventricular diastolic functions and found restrictive-type abnormalities, although their systolic functions were partially intact. Generally, cardiac complications due to chemotherapy and/or radiotherapy are manifested about 10 years after completion of treatment. ${ }^{16}$ In our study, patients were examined at least five years after completion of treatment, and we are curious whether these complications would increase if we were to evaluate them in later years. It is interesting that there was no significant difference between Groups 1 and 2; this suggested that our radiotherapy techniques and radiation doses did not have any deleterious side-effects.

In conclusion, the main aim of treatment of malignancy during childhood or adolescence is to cure the patient, permitting normal development to occur and leading to a useful and productive adult life. In our patient group the late effects of COPP chemotherapy and mantle irradiation using current treatment techniques appear to be minimal and, at this point in time, without clinical significance. We propose that especially those abnormalities which begin in diastolic functions may effect systolic functions later. The late effects of treatment may thus be shown to be greater when more sensitive techniques are used and when more time has elapsed since the end of treatment.

Cardiac effects after treatment for childhood Hodgkin's disease

- pericarditis, pericardial effusion

- ECG abnormalities

- cardiomyopathy

- valvular disease

- coronary artery stenoses

6 Applefeld MM, Slawson RG, Hall-Craigs, et al. Delayed pericardial disease after radiotherapy. Am $\mathrm{f}$ Cardiol 1981 ; 47: $210-4$.

7 McReynolds RA, Gold GL, Roberts WC. Coronary heart disease after mediastinal irradiation for Hodgkin's disease. Am ₹ Med 1976; 60: 39-45.

8 Yahalom J, Hasin Y, Fuks Z. Acute myocardial infarction with normal coronary arteriogram after mantle field radiation therapy for Hodgkin's disease. Cancer 1983, 52: 637-41.

9 Braunwald E. Heart disease. A textbook of cardiovascular medicine. Tokyo: WB Saunders Company, 1992, p 11.

10 Applefeld MM, Wiernk PH. Cardiac disease after radiation therapy for Hodgkin's disease; analysis of 48 patients. $A m \mathcal{F}$ Cardiol 1981; 47: 210-3.
Carapy for Hodgkin's dis

11 Pohjola-Sintonen S, Tötterman KJ, Salmo M, Siltanen P. Late cardiac effects of mediastinal radiotherapy in patients with Hodgkin's disease. Cancer 1987; 60: 31-7. 
12 Gottdiener JS, Katin MJ, Borer JS, Bagharach SL, Green MV. Late cardiac effects of therapeutic mediastinal irradiation. $N$ Engl $₹$ Med 1983; 308: 569-72.

13 Stewart JR, Fajardo LF. Radiation-induced heart disease; an update. Progr Cardiovasc Dis 1984; 27: 173-194.

14 Burns RJ, Bar-Shlomo BZ, Druck MN, et al. Detection of radiation cardiomyopathy by gated radionuclide angiography. Am f Med 1983; 74: 297-302.
15 Hancok SL, Donaldson SS, Hoppe RT. Cardiac disease following treatment of Hodgkin's disease in children and adolescent. ₹ Clin Oncol 1993; 11: 1208-15.

16 Lipshultz SE, Sallan SE. Cardiovascular abnormalities in long-term survivors of childhood malignancy. $\mathcal{f}$ Clin Oncol 1993; 11: 1199-1203.

\section{Medical Anniversary SVEN LOFGREN, 1 March 1910}

Sven Lofgren (1910-78) was born in Stockholm where he received his medical training and where he married a Swedish physician, who bore him four children. His medical life revolved around St Goran's Hospital where he came under the scientific influence of Westergren and Schaumann. Sven grasped the baton handed to him by Schaumann and his own elegant studies brought the mysterious disease sarcoidosis out of the shadows and into the limelight as a common disorder with a good prognosis. During the war years he analysed 185 cases of erythema nodosum and found 15 patients in whom sarcoidosis was probable, despite lack of histological proof. In a second Swedish survey published in 1953 he obtained histological proof of sarcoid tissue in one-quarter of a series of 113 patients with erythema nodosum and bilateral hilar lymphadenopathy and, quite rightly, this combination has been known as Lofgren's syndrome ever since. Once he had defined it, the rest of the world recognised it.

Lofgren died on 17 June 1978. His lifework was at St Goran's Hospital, where he succeeded Westergren as head of the lung clinic and where he inherited from Schaumann the old roll-top desk which was a permanent feature of Sven's office furniture. I wonder who uses it now? Schaumann donated more than just his roll-top desk for they were good friends and colleagues at St Goran's. Schaumann (1879-1953) was the old experienced dermatologist turned multisystem physician and Lofgren the young chest physician. In 1971, Sven was awarded the title of Professor, an unusual honour in Sweden for a physician practising outside a university department. 